\title{
Is pulse oximeter a reliable tool for non-critically ill patients with COVID-19?
}

\author{
Aslıhan Gürün Kaya ${ }^{1}$, Miraç Öz ${ }^{2}$, İREM AKDEMİR KALKAN², Ezgi Gülten², güle \\ $\mathrm{AYDIN}^{2}$, Alpay Azap ${ }^{2}$, and Akin Kaya ${ }^{2}$ \\ ${ }^{1}$ Affiliation not available \\ ${ }^{2}$ Ankara University Faculty of Medicine
}

September 24, 2021

\begin{abstract}
Introduction: Guidelines recommend using a pulse oximeter rather than arterial blood gas (ABG) for COVID-19 patients. However, significant differences can be observed between oxygen saturation measured by pulse oximetry (SpO2) and arterial oxygen saturation $(\mathrm{SaO} 2)$ in some clinical conditions. We aimed to assess the reliability of pulse oximeter in patients with COVID-19 Methods: We retrospectively reviewed ABG analyses and SpO2 levels measured simultaneously with ABG in patients hospitalized in COVID-19 wards. Results: We categorized total 117 patients into two groups; in whom the difference between $\mathrm{SpO} 2$ and $\mathrm{SaO} 2$ was $? 4 \%$ (acceptable difference) and $>4 \%$ (large difference). Large difference group exhibited higher neutrophil count, C-reactive protein, ferritin, fibrinogen, D-dimer and lower lymphocyte count. Multivariate analyses revealed that increased fibrinogen, increased ferritin and decreased lymphocyte count were independent risk factors for large difference between $\mathrm{SpO} 2$ and $\mathrm{SaO} 2$. The total study group demonstrated the negative bias of $4.02 \%$ with the limits of agreement of $-9.22 \%$ to $1.17 \%$. The bias became significantly higher in patients with higher ferritin, fibrinogen levels and lower lymphocyte count. Conclusion: Pulse oximeters may not be sufficient to assess actual oxygen saturation especially in COVID-19 patients with high ferritin and fibrinogen levels and low lymphocyte count low SpO2 measurements.
\end{abstract}

Title of Paper: Is pulse oximeter a reliable tool for non-critically ill patients with COVID-19?

\section{Abstract}

Introduction: Guidelines recommend using a pulse oximeter rather than arterial blood gas (ABG) for COVID-19 patients. However, significant differences can be observed between oxygen saturation measured by pulse oximetry $\left(\mathrm{SpO}_{2}\right)$ and arterial oxygen saturation $\left(\mathrm{SaO}_{2}\right)$ in some clinical conditions. We aimed to assess the reliability of pulse oximeter in patients with COVID-19

Methods: We retrospectively reviewed ABG analyses and SpO2 levels measured simultaneously with ABG in patients hospitalized in COVID-19 wards.

Results : We categorized total 117 patients into two groups; in whom the difference between $\mathrm{SpO}_{2}$ and $\mathrm{SaO}_{2}$ was [?] $4 \%$ (acceptable difference) and $>4 \%$ (large difference). Large difference group exhibited higher neutrophil count, C-reactive protein, ferritin, fibrinogen, D-dimer and lower lymphocyte count. Multivariate analyses revealed that increased fibrinogen, increased ferritin and decreased lymphocyte count were independent risk factors for large difference between $\mathrm{SpO}_{2}$ and $\mathrm{SaO}_{2}$. The total study group demonstrated the negative bias of $4.02 \%$ with the limits of agreement of $-9.22 \%$ to $1.17 \%$. The bias became significantly higher in patients with higher ferritin, fibrinogen levels and lower lymphocyte count.

Conclusion: Pulse oximeters may not be sufficient to assess actual oxygen saturation especially in COVID19 patients with high ferritin and fibrinogen levels and low lymphocyte count low $\mathrm{SpO}_{2}$ measurements. 
Keywords pulse oximeter, hypoxemia, oxygen saturation, arterial blood gas, coronavirus, COVID-19

\section{What' known?}

Arterial blood gas (ABG) analyses remain the gold standard for the measurement of oxygen saturation. The pulse oximeter is a non-invasive alternative to ABG analysis to assess oxygenation in clinical practice. Especially in patients with COVID-19, monitoring oxygenation status by pulse oximetry is essential to detect any clinical deterioration early.

\section{What's new?}

The pulse oximeter can underestimate the arterial oxygen saturation obtained from ABG analysis in noncritically ill patients who were hospitalized due to COVID-19. Increased fibrinogen and ferritin levels, decreased lymphocyte count were associated with large $\mathrm{SpO} 2-\mathrm{SaO} 2$ difference $(>4 \%)$.

\section{Main text}

\section{Introduction}

Coronavirus disease 2019 (COVID-19) caused by severe acute respiratory syndrome coronavirus 2 (SARSCoV-2), has quickly become a global pandemic since it was first reported in December 2019. Patients with COVID-19 need different levels of hospital care because of hypoxemic respiratory failure ${ }^{1}$. Monitoring oxygenation status and providing effective oxygen therapy on time is also essential on these patients ${ }^{2}$. Arterial blood gas analysis (ABG) is considered the gold standard in assessing oxygenation but it is an invasive, painful, and expensive procedure therefore inconvenient for frequent monitorization. Pulse oximeter has been developed as a safer noninvasive alternative to ABG analysis and has become the standard of care to assess oxygenation in clinical practice, which utilizes the different light absorption of spectra of oxygenated and deoxygenated hemoglobin. It was found that the expected error for a single measurement of oxygen saturation measured by pulse oximetry $\left(\mathrm{SpO}_{2}\right)$ is $3 \%-4 \%$. But, the deviation of $\mathrm{SpO}_{2}$ from oxygen saturation in the arterial blood $\left(\mathrm{SaO}_{2}\right)$ is even more significant at saturations below 70\%. Furthermore, $\mathrm{SpO} 2$ can underestimate $\mathrm{SaO}_{2}$ in low perfusion states, arrhythmias, vasoconstriction, edema and severe anemia ${ }^{3-5}$.

In our clinic, we observed that $\mathrm{SpO}_{2}$ levels were lower than the $\mathrm{SaO}_{2}$ in most COVID-19 patients. A study by Wilson-Baig et al. suggested that $\mathrm{SpO}_{2}$ does not reliably predict $\mathrm{SaO}_{2}$ in critical care patients with COVID-196 . Also, previous data proposed that $\mathrm{SpO}_{2}$ is an unreliable surrogate marker for $\mathrm{SaO} 2$ in critically ill patients ${ }^{7}$. But the data is lacking about $\mathrm{SpO}_{2}$ accuracy in hospitalized non-critically ill COVID-19 patients.

We aimed to determine the reliability of pulse oximetry in non-critically ill patients who were hospitalized in wards due to COVID-19.

\section{Subjects and Methods}

\section{Study participants}

We retrospectively reviewed patients hospitalized in the COVID-19 wards of Ankara University Faculty of Medicine from 1 September 2020 to 31 January 2021. Among patients with confirmed COVID-19 infection based on a positive real-time reverse transcriptase-polymerase chain reaction (RT-PCR) testing, the patients whose ABG was sampled during their hospitalization and simultaneously $\mathrm{SpO}_{2}$ measurement by pulse oximetry was recorded were enrolled in the study. The following patients were excluded from the study: patients with hypotension (mean arterial pressure $<65 \mathrm{mmHg}$ ); patients with hypothermia (body temperature $<35$ $\left.{ }^{0} \mathrm{C}\right)$; patients with low hemoglobin level $(\mathrm{Hb}<10 \mathrm{gr} / \mathrm{dL})$; patients with hematological malignancy; patients with peripheral vascular disease; patients who had been under long-term oxygen therapy due to chronic respiratory failure, patients with connective tissue disease that can affect skin thickness and peripheral vascular structures, patients with methemoglobinemia, and patients with missing laboratory data. The study was approved by the Human Research Ethics Committee of Ankara University (16.02.21/12-129-21).

\section{Clinical and Laboratory Data}


Demographic features and comorbid conditions of the patients, the date of hospitalization, the date of symptom onset, the date of ABG sampling, the results of $\mathrm{ABG}$ analysis, $\mathrm{SpO}_{2}$ level measured simultaneously with ABG, the laboratory results (hemogram, C-reactive protein-CRP, D-dimer, fibrinogen and ferritin) for the same day of ABG sampling, anticoagulant therapy status, and the outcome of the disease (death, transfer to ICU, or discharge) obtained from patients' hospital file and electronic medical record system of the hospital were recorded on a data form.

\section{Arterial blood gas analyses and measurement of $\mathrm{SpO} 2$}

As a routine practice of our clinic, ABG samples were taken from punctures of the radial artery without placing an arterial catheter. Brachial or femoral artery were punctured when arterial blood could not be taken from the radial artery. The indications of $\mathrm{ABG}$ sampling in our clinic were as follows: a $\mathrm{SpO}_{2}$ below $90 \%$, presence of unexplained or clinically inconsistent hypoxemia, a significant increase in the fraction of inspired oxygen $\left(\mathrm{FiO}_{2}\right)$ to achieve target oxygen saturation; the presence of acute dyspnea, lethargy or other signs of carbon dioxide retention in a patient with risk factors for hypercapnic respiratory failure and patients at risk for metabolic conditions. If the patient required any oxygen supplementation, oxygen therapy was administered via low flow oxygen systems, including a nasal cannula, simple face mask or non-rebreathing mask with the target oxygen saturation $>90 \%$. All the ABG samples were analyzed within 15 minutes with using the ABL800 blood gas analyzers (Radiometer Medical ApS, Denmark).

As our standard of care in wards, blood pressure, heart rate, body temperature and $\mathrm{SpO}_{2}$ of patients were measured and recorded to patients' files at least four times a day. The number of these measurements was increased according to the patients' clinical condition. In addition to these daily measurements, $\mathrm{SpO}_{2}$ was measured simultaneously with ABG sampling and recorded. We routinely placed two pulse oximetry probes on both hands finger for at least two measurements of $\mathrm{SpO}_{2}$ using finger pulse oximeters (Contec CMS50D Fingertip Pulse Oximeter, Qinhusangdao, China). Then the mean of SpO2 measurements was recorded to reduce the risk of measurement error.

\section{Statistical analyses}

The data was analyzed using SPSS 22.0 software (SPSS, Inc., Chicago, IL, USA). Continuous variables with normal distribution were presented as mean \pm standard deviation and median [25th-75th percentiles, interquartile range (IQR)] for non-normal variables. Kolmogorov- Smirnov test was used to analyze the distribution of variables and a Levene test to assess the equality of variances. An unpaired Student's t-test or a Mann-Whitney U test was used to compare the two groups. Categorical data were expressed as numbers and percentages and compared by chi-square test or Fisher's exact test as appropriate. We compared the demographic and clinical features between subjects that showed a difference between $\mathrm{SpO}_{2}$ and $\mathrm{SaO}_{2}$ [?] $4 \%$ (acceptable difference) or $>4 \%$ (large difference). This cut-off value was chosen due to a potential error of 3-4\% between $\mathrm{SpO}_{2}$ and $\mathrm{SaO}_{2}$ according to the previous data ${ }^{8-10}$. The relationships between age, gender and comorbid diseases and laboratory data with large difference between $\mathrm{SpO}_{2}$ and $\mathrm{SaO}_{2}$ were analyzed using binary logistic regression analyses. We used a receiver operating characteristic curve analysis to determine the optimal cut-off value of fibrinogen, ferritin, D-dimer levels, and lymphocyte counts to predict large differences between $\mathrm{SpO}_{2}$ and $\mathrm{SaO}_{2}(>4 \%)$ the best combination of sensitivity and specificity. Bland Altman method was performed to display bias (systematic error - mean difference between $\mathrm{SpO}_{2}$ and $\mathrm{SaO}_{2}$ ), precision (random error - standard deviation of mean difference) were calculated. Limits of agreement were defined at mean difference $+-2 \mathrm{SD}$.

The statistical significance level was expressed as $\mathrm{p}<0.05$ for all tests.

\section{Results}

A total of 174 patients with COVID-19 required ABG sampling in our hospital wards during the study period. After the exclusion of 57 patients, a total of 117 patients' data was evaluated (Figure 1). The mean age of study patients was $69.4+-12.0$ years, and $65 \%$ (n:76) were male. Of all study patients, 97 $(82.9 \%)$ had at least one comorbid disease. The computed tomography findings of thorax were compatible 
with COVID-19 pneumonia in 110 (94\%) patients. The patients were hospitalized at the median 4th [2-6] day, and the ABG samples were analyzed at the median 11th [8-15] day after symptom onset. Among the patients, $98.3 \%$ received anticoagulant, and $45.3 \%$ received antiaggregant agents during hospitalization.

Twenty-nine (24.8\%) patients were transferred to the intensive care units and 14 (12.0\%) died.

The median $\mathrm{SpO}_{2}$ and $\mathrm{SaO}_{2}$ levels of the patients were 88\% [84-88] and 91.8\% [88.3-94.4], respectively. In 10 out of 117 patients, $\mathrm{SpO}_{2}$ levels were higher than $\mathrm{SaO}_{2}$ (mean difference 1.1+-0.7\%). We categorized the patients into two groups; in whom the difference between $\mathrm{SaO}_{2}$ and $\mathrm{SpO}_{2}$ was [?]4\% (acceptable difference group) and $>4 \%$ (large difference group). In 59 patients (50.4\%), the difference between $\mathrm{SpO}_{2}$ and $\mathrm{SaO}_{2}$ measurements was greater than $4 \%$ (large difference), and within this group, all $\mathrm{SaO}_{2}$ levels measured were higher than $\mathrm{SpO}_{2}$. The baseline features and comorbid conditions of these two groups were given in Table 1.

Patients with large difference have higher neutrophil count d-dimer, ferritin, fibrinogen and C-reactive protein (CRP) level than the patients with an acceptable difference (Table 2). To determine the effect of clinical and laboratory parameters on large difference risk, a binary logistic regression analysis was employed; revealing that increased d-dimer, fibrinogen, ferritin level and decreased lymphocyte count were significantly associated with large difference between $\mathrm{SpO}_{2} \& \mathrm{SaO}_{2}$ (Table 3).

We performed receiver operating characteristic (ROC) curve analyses to determine cut-off values for ferritin, fibrinogen and lymphocyte count that would predict large difference between $\mathrm{SpO}_{2}$ and $\mathrm{SaO}_{2}$. The best cut-off value was $4.8 \mathrm{~g} / \mathrm{dL}$ (area under curve-AUC: $0.761,95 \%$ CI: $0.674-0.848, \mathrm{p}<0.001$, sensitivity:71\%; specificity:73\%) for fibrinogen, $228 \mathrm{~g} / \mathrm{dL}$ (AUC: 0.813, 95\% CI: 0.734-0.892, p < 0.001, sensitivity:86\%; specificity:57\%) for ferritin, and 1,04 x 10 $/ \mathrm{mm}^{3}$ (AUC: 0.806, 95\% CI: 0.722-0.890, p < 0.001, sensitivity:86\%; specificity:70\%) for lymphocyte count.

Bland-Altman analysis comparing $\mathrm{SpO}_{2}$ with $\mathrm{SaO}_{2}$ within the total study group demonstrated the negative bias (mean difference) of $4.02 \%$ with an SD of 2.65 (precision) and the limits of agreement of $-9.22 \%$ to $1.17 \%$ (Figure 2). This indicates that the $\mathrm{SpO}_{2}$ underestimated $\mathrm{SaO}_{2}$ value by an average $4.02+-2.65 \%$ and limits of agreement were clinically important since $\mathrm{SpO}_{2}$ could be measured $9 \%$ lower or $1 \%$ greater than actual arterial oxygen saturation. Also, we performed Bland-Altman analyses to calculate mean differences and precision separately in subgroups of patients with increased and normal serum ferritin, with increased and normal serum fibrinogen; normal and decreased lymphocyte count. The results showed a significant increase of the bias in patients with high fibrinogen level, high ferritin level and low lymphocyte count compared those with normal values (Figure 3, Figure 4 and Figure 5, respectively). Within all subgroups, we showed that $\mathrm{SpO}_{2}$ underestimated $\mathrm{SaO}_{2}$. These finding suggested that the reliability of pulse oximeter is further reduced in patients with high fibrinogen, high ferritin and low lymphocyte count.

\section{Discussion}

The present study showed that oxygen saturation measured by pulse oximetry underestimated the arterial oxygen saturation obtained from ABG analysis in non-critically ill patients who were hospitalized due to COVID-19. Increased fibrinogen and ferritin level, decreased lymphocyte count were independently associated with large $\mathrm{SpO}_{2}-\mathrm{SaO}_{2}$ difference $(>4 \%)$. Bland-Altman analysis comparing $\mathrm{SpO}_{2}$ with $\mathrm{SaO}_{2}$ within the total study group demonstrated the negative bias of $4.02 \%$ with limits of agreement of $-9.22 \%$ to 1.17 $\%$. The bias became significantly higher in patients with higher ferritin, fibrinogen, and lower lymphocyte count.

Hypoxemia is one of the hallmarks of severe COVID-19. Patients hospitalized in hospital wards due to severe disease should be monitored closely for vital signs, including oxygen saturation to detect any worsening or respiratory failure ${ }^{11,12}$. ABG analyses remain the gold standard for measurement of oxygen saturation, but it is invasive and painful therefore inconvenient for frequent monitorization. Pulse oximeters are widely used as standard medical instrument for noninvasively monitoring arterial oxygen saturation $\left(\mathrm{SpO}_{2}\right)$. Previous studies suggested that pulse oximetry is an accurate method to assess $\mathrm{SaO}_{2}$ in most adult patients in the clinical setting. However, studies indicated clinically meaningful differences between $\mathrm{SpO}_{2}$ and $\mathrm{SaO}_{2}$ in 
some clinical conditions such as sepsis, septic shock, hyperbilirubinemia, anemia, and hypovolemia ${ }^{4,13,14}$. Guidelines recommend using a pulse oximeter rather than invasive ABG for the monitoring of COVID-19 patients, unless there is a suspicion of carbon dioxide retention ${ }^{15,16}$.

Wilson-Baig and colleagues reported 17 patients with COVID-19 pneumonia under critical care suggesting that $\mathrm{SpO}_{2}$ is underestimating $\mathrm{SaO}_{2}$ by a mean difference of $5.3 \%$ with $95 \%$ limits of agreement. They explained their findings with possible different spectral properties of high ferritin, d-dimer or other proteins at $660 \mathrm{~nm}$ and $940 \mathrm{~nm}$; arteriolar dilatation and microvascular complications secondary to tissue hypoxia in patients with COVID-19 ${ }^{6}$. Recently, Philip et al. reported another study evaluating the accuracy of pulse oximeter for stepping down from critical care in patients with COVID-19. In this study, it was reported that pulse oximetry has a slightly suboptimal level of agreement with $\mathrm{SaO}_{2}$ measurement (bias of $0.4 \%$ with limits of agreement of $-4.3 \%$ to $5.2 \%$ ). The authors expressed potential causes of differences in their study including skin color of patients, the allowable time between $\mathrm{SpO}_{2}$ and $\mathrm{SaO}_{2}$ measurement of up to 15 minutes, the peripheral vasoconstriction due to hypothermia or vasopressor use. However the authors emphasized that their study aimed to determine the limits of agreement of the pulse oximeter, so the possible factors that caused suboptimal measurement were not evaluated in the study ${ }^{17}$. In both studies on the reliability of pulse oximetry in COVID-19, the laboratory findings of the patients were not evaluated.

To our current knowledge, hyperinflammation and coagulopathy are responsible for disease severity on the pathogenesis of COVID-19. SARS-CoV-2 lead systemic inflammation and diffuse microvascular thrombosis by triggering a unique endothelial response; endothelial exocytosis, which simultaneously activates 2 parallel pathways. Also, inflammatory cytokines releasing from endothelium, are the major mediators involved in coagulation activation ${ }^{18}$. Consistently, patients with moderate to severe COVID-19 often have hypercoagulable state, suggesting widespread thrombosis and fibrinolysis, as well as elevated levels of D-dimer and fibrinogen ${ }^{19,20}$. Fibrinogen is a macromolecular plasma protein that causes increase in blood viscosity or stasis, especially in microvascular structures by causing erythrocytes to form large aggregates, called rouleaux 21,22. D-dimer is a degradation product of fibrin, reflecting the coagulation system's turnover and previous data showed D-dimer might be used as a marker of microcirculatory failure ${ }^{23}$. Besides coagulation markers, ferritin, CRP, IL-6 levels are used as biomarkers of inflammation, and the increased levels of these biomarkers predict disease severity in COVID-19 ${ }^{24}$. Decreased lymphocyte count is also associated with COVID-19 severity and a predictor of hyperinflammation ${ }^{25}$. As a result of these mechanisms and published studies, increased ferritin, CRP, fibrinogen, D-dimer levels and decreased lymphocyte count are known to be clinical predictors of disease severity ${ }^{26-28}$.

Based on the previous data and results of our study, we hypothesize that, causing microvascular damage and perfusion impairment related inflammation and hypercoagulation may be the cause of large measurement difference of $\mathrm{SpO}_{2}$ and $\mathrm{SaO}_{2}$ in patients with COVID-19. This difference may tend to be greater in the presence of ferritin, fibrinogen, D-dimer elevation and lymphopenia, which indicate increased severity of inflammation and hypercoagulability. Also, as Wilson-Baig et al. emphasized, different spectral properties of these serum proteins might have caused errors in the measurement of the oximeter ${ }^{6}$. Further physiological studies are required to support this view.

Another point to mention, our study group $(\mathrm{N}=117)$ showed negative bias on difference between $\mathrm{SpO}_{2}$ and $\mathrm{SaO}_{2}$. In only 10 patients (8.54\%), $\mathrm{SpO}_{2}$ levels were measured higher than $\mathrm{SaO}_{2}$ with mean difference $1.1+-0.7 \%$. Studies of pulse oximeter accuracy in different patient groups have shown mixed results; while some studies have found that $\mathrm{SpO}_{2}$ has overestimated $\mathrm{SaO}_{2}$, others have found the opposite ${ }^{9,29-31}$. Similar to our research, both two previous studies evaluating pulse oximetry in COVID-19 revealed that $\mathrm{SpO}_{2}$ underestimated the $\mathrm{SaO}_{2}$ level ${ }^{6,17}$. This situation may also cause clinically inconsistent hypoxemia in a group of COVID-19 patients, which has also been described as silent hypoxemia. We think pulse oximetry may not be sufficient to assess actual oxygen saturation in hospitalized COVID-19 patients, especially with increased inflammatory and coagulation biomarkers.

To the best of our knowledge, this is the first study to compare $\mathrm{SpO}_{2}$ and $\mathrm{SaO}_{2}$ in non-critically ill COVID19 patients. As distinct from two previous studies with COVID patients in intensive care ${ }^{9,24}$, the present 
study included a higher number of patients and additionally the $\mathrm{SpO}_{2}-\mathrm{SaO}_{2}$ difference was evaluated with the laboratory parameters.

Our study has some limitations. First, this study conducted retrospectively and we evaluated the blood pressure and body temperature on a daily record of patients' file, but real-time data was lacking. The other limitation was, we measured patients $\mathrm{SpO}_{2}$ via same pulse oximeter type, and we do not know whether the results would differ if we used another model pulse oximeter. On the other hand, the pulse oximeters in our wards were approved by Food and Drug Administration (FDA) and European Conformity (CE). The third limitation of the study was that it did not have a control group with non-COVID to compare results.

To conclude, pulse oximetry may not be sufficient to assess actual oxygen saturation in hospitalized COVID19 patients. Therefore, especially in patients with high ferritin and fibrinogen levels and low lymphocyte count low $\mathrm{SpO}_{2}$ measurements may be confirmed by ABG. Further studies are needed to assess discrepancies of $\mathrm{SpO}_{2}$ and $\mathrm{SaO}_{2}$ in COVID-19.

Conflict of interest: Authors declared no conflict of interest

\section{References}

1. Yeh CH, de Wit K, Levy JH, et al. Hypercoagulability and coronavirus disease 2019-associated hypoxemic respiratory failure: Mechanisms and emerging management paradigms. J Trauma Acute Care Surg.2020;89(6):e177-e181.

2. Li X, Li T, Wang H. Treatment and prognosis of COVID-19: Current scenario and prospects (Review). Exp Ther Med. 2021;21(1):3.

3. Nitzan M, Romem A, Koppel R. Pulse oximetry: fundamentals and technology update. Med Devices (Auckl). 2014;7:231-239.

4. Hess DR. Pulse Oximetry: Beyond SpO2. Respir Care.2016;61(12):1671-1680.

5. Chan ED, Chan MM, Chan MM. Pulse oximetry: understanding its basic principles facilitates appreciation of its limitations. Respir Med. 2013;107(6):789-799.

6. Wilson-Baig N, McDonnell T, Bentley A. Discrepancy between Sp O2 and Sa O2 in patients with COVID19. Anaesthesia. 2020;[Epub ahead of print].

7. Thijssen M, Janssen L, Noble J, N F. Facing SpO2 and SaO2 discrepancies in ICU patients: is the perfusion index helpful? J Clin Monit Comput. 2020;34 (4):693-698.

8. Seguin P, Le Rouzo A, Tanguy M, Guillou YM, Feuillu A, Malledant Y. Evidence for the need of bedside accuracy of pulse oximetry in an intensive care unit. Crit Care Med. 2000;28(3):703-706.

9. Van de Louw A, Cracco C, Cerf C, et al. Accuracy of pulse oximetry in the intensive care unit. Intensive Care Med.2001;27(10):1606-1613.

10. Yossef Hay O, Cohen M, Nitzan I, et al. Pulse Oximetry with Two Infrared Wavelengths without Calibration in Extracted Arterial Blood.Sensors (Basel). 2018;18(10).

11. Gandhi RT, Lynch JB, Del Rio C. Mild or Moderate Covid-19. N Engl J Med. 2020;383(18):1757-1766.

12. National Institutes of Health COVID-19 Treatment Guidelines: Clinical Spectrum of SARS-CoV-2 Infection. 2020. Accessed 5 February 2020.

13. Wilson BJ, Cowan HJ, Lord JA, Zuege DJ, Zygun DA. The accuracy of pulse oximetry in emergency department patients with severe sepsis and septic shock: a retrospective cohort study. BMC Emerg Med.2010;10:9.

14. Mutlu GM, Sznajder JI. Pseudohypoxemia: interpretation of discrepancies between $\mathrm{SaO}(2)$ and $\mathrm{SpO}(2)$. Tuberk Toraks.2005;53(2):185-189. 
15. NHS England. Specialty guides for patient management during the coronavirus pandemic: Guidance for the role and use of non-invasive respiratory support in adult patients with COVID19 (confirmed or suspected) Publications approval reference: 001559. 2020.

16. Turkey Ministry of Health Guidelines: COVID-19 (SARS-CoV-2 Infection) Treatment of Adult Patients 12 October 2020. https://covid19.saglik.gov.tr/Eklenti/39061/0/covid-19rehberieriskinhastatedavisipdf.pdf. Accessed 8 February 2021.

17. Philip KEJ, Bennett B, Fuller S, et al. Working accuracy of pulse oximetry in COVID-19 patients stepping down from intensive care: a clinical evaluation. BMJ Open Respir Res. 2020;7(1).

18. Lowenstein CJ, Solomon SD. Severe COVID-19 Is a Microvascular Disease. Circulation. 2020;142(17):1609-1611.

19. Varga Z, Flammer AJ, Steiger P, et al. Endothelial cell infection and endotheliitis in COVID-19. Lancet. 2020;395(10234):1417-1418.

20. Escher R, Breakey N, Lammle B. Severe COVID-19 infection associated with endothelial activation. Thromb Res. 2020;190:62.

21. Brust M, Aouane O, Thiebaud M, et al. The plasma protein fibrinogen stabilizes clusters of red blood cells in microcapillary flows.Sci Rep. 2014;4:4348.

22. Lominadze D, Dean WL, Tyagi SC, Roberts AM. Mechanisms of fibrinogen-induced microvascular dysfunction during cardiovascular disease. Acta Physiol (Oxf). 2010;198(1):1-13.

23. Angstwurm MW, Reininger AJ, Spannagl M. D-dimer as marker for microcirculatory failure: correlation with LOD and APACHE II scores. Thromb Res. 2004;113(6):353-359.

24. Esmon CT. The impact of the inflammatory response on coagulation. Thromb Res. 2004;114(5-6):321-327.

25. Gorlinger K, Dirkmann D, Gandhi A, Simioni P. COVID-19-Associated Coagulopathy and Inflammatory Response: What Do We Know Already and What Are the Knowledge Gaps? Anesth Analg. 2020;131(5):1324-1333.

26. Ji P, Zhu J, Zhong Z, et al. Association of elevated inflammatory markers and severe COVID-19: A meta-analysis. Medicine (Baltimore). 2020;99(47):e23315.

27. Mudatsir M, Fajar JK, Wulandari L, et al. Predictors of COVID-19 severity: a systematic review and meta-analysis. F1000Res.2020;9:1107.

28. Broman N, Rantasarkka K, Feuth T, et al. IL-6 and other biomarkers as predictors of severity in COVID-19. Ann Med. 2020:1-5.

29. Seifi S, Khatony A, Moradi G, Abdi A, Najafi F. Accuracy of pulse oximetry in detection of oxygen saturation in patients admitted to the intensive care unit of heart surgery: comparison of finger, toe, forehead and earlobe probes. BMC Nurs. 2018;17:15.

30. Ascha M, Bhattacharyya A, Ramos JA, Tonelli AR. Pulse Oximetry and Arterial Oxygen Saturation during Cardiopulmonary Exercise Testing. Med Sci Sports Exerc. 2018;50(10):1992-1997.

31. Singh AK, Sahi MS, Mahawar B, Rajpurohit S. Comparative Evaluation of Accuracy of Pulse Oximeters and Factors Affecting Their Performance in a Tertiary Intensive Care Unit. $J$ Clin Diagn Res.2017;11(6):OC05-OC08.

Table 1. Demographic characteristics and comorbid conditions of patients with an acceptable difference ([?]4\%) and large difference $(>4 \%)$ 


\begin{tabular}{|c|c|c|c|}
\hline & $\begin{array}{l}\left|\mathrm{SpO}_{2}-\mathrm{SaO}_{2}\right|[?] 4 \%(\mathrm{n}: \\
58)\end{array}$ & $\begin{array}{l}\left|\mathrm{SpO}_{2}-\mathrm{SaO}_{2}\right|>4 \%(\mathrm{n}: \\
59)\end{array}$ & $\mathrm{p}$ \\
\hline Age & $69.45 \pm 12.13$ & $69.41 \pm 11.97$ & 0.985 \\
\hline Gender (male) & $31(53.4 \%)$ & $45(76.3 \%)$ & 0.010 \\
\hline $\begin{array}{l}\text { Any comorbid } \\
\text { disease }\end{array}$ & $48(82.8 \%)$ & $49(83.1 \%)$ & 0.999 \\
\hline Hypertension & $35(60.3 \%)$ & $40(67.8 \%)$ & 0.401 \\
\hline Diabetes mellitus & $18(31.0 \%)$ & $24(40.7 \%)$ & 0.277 \\
\hline $\begin{array}{l}\text { Obstructive lung } \\
\text { disease }\end{array}$ & $14(24.1 \%)$ & $9(15.3 \%)$ & 0.227 \\
\hline $\begin{array}{l}\text { Chronic heart } \\
\text { disease }^{+}\end{array}$ & $23(39.7 \%)$ & $20(33.9 \%)$ & 0.518 \\
\hline $\begin{array}{l}\text { Chronic renal } \\
\text { failure }\end{array}$ & $4(6.9 \%)$ & $6(10.2 \%)$ & 0.743 \\
\hline Malignancy $^{++}$ & $5(8.6 \%)$ & $8(13.6 \%)$ & 0.395 \\
\hline $\begin{array}{l}{ }^{+} \text {heart failure, } \\
\text { coronary artery disease }\end{array}$ & $\begin{array}{l}\text { +heart failure, } \\
\text { coronary artery disease }\end{array}$ & $\begin{array}{l}{ }^{+} \text {heart failure, } \\
\text { coronary artery disease }\end{array}$ & $\begin{array}{l}{ }^{+} \text {heart failure, } \\
\text { coronary artery disease }\end{array}$ \\
\hline${ }^{++} \cdot$ nonsmall lung & ${ }^{++} \cdot$ nonsmall lung & ${ }^{++} \cdot$ nonsmall lung & ${ }^{++} \cdot$ nonsmall lung \\
\hline $\begin{array}{l}\text { cancer, colon cancer, } \\
\text { stomach cancer, }\end{array}$ & $\begin{array}{l}\text { cancer, colon cancer, } \\
\text { stomach cancer, }\end{array}$ & $\begin{array}{l}\text { cancer, colon cancer, } \\
\text { stomach cancer, }\end{array}$ & $\begin{array}{l}\text { cancer, colon cancer, } \\
\text { stomach cancer, } \\
\text { mandibular squamous }\end{array}$ \\
\hline $\begin{array}{l}\text { mandibular squamous } \\
\text { cell cancer, prostate }\end{array}$ & $\begin{array}{l}\text { mandibular squamous } \\
\text { cell cancer, prostate }\end{array}$ & $\begin{array}{l}\text { mandibular squamous } \\
\text { cell cancer, prostate }\end{array}$ & $\begin{array}{l}\text { mandibular squamous } \\
\text { cell cancer, prostate }\end{array}$ \\
\hline cancer and & cancer and & cancer and & cancer and \\
\hline mesothelioma & mesothelioma & mesothelioma & mesothelioma \\
\hline
\end{tabular}

Table 2. Comparing ABG and other laboratory parameters of patients with an acceptable difference ([?]4\%) and large difference $(>4 \%)$

\begin{tabular}{|c|c|c|c|}
\hline & $\begin{array}{l}\left|\mathrm{SpO}_{2}-\mathrm{SaO}_{2}\right|[?] 4 \%(\mathrm{n}: \\
58)\end{array}$ & $\begin{array}{l}\left|\mathrm{SpO}_{2}-\mathrm{SaO}_{2}\right|>4 \%(\mathrm{n}: \\
59)\end{array}$ & $\mathrm{p}$ \\
\hline \multicolumn{4}{|l|}{ ABG } \\
\hline pH & $7.44[7.39-7.46]$ & $7.44[7.41-7.47]$ & 0.460 \\
\hline $\mathrm{PaO}_{2}(\mathrm{mmHg})$ & 60.50 [52.37-69.90] & $60.20[51.90-70.30]$ & 0.677 \\
\hline $\mathrm{PaCO}_{2}(\mathrm{mmHg})$ & $33.60[28.95-36.95]$ & $31.80[29.20-37.50]$ & 0.376 \\
\hline $\mathrm{SaO}_{2}(\%)$ & $91.4[86.70-94.17]$ & $92.60[88.70-94.80]$ & 0.227 \\
\hline HCO3 ( $\mathbf{m E q} / \mathrm{L})$ & $24.10[22.20-25.70]$ & $24.50[22.20-26.30]$ & 0.549 \\
\hline Lactate $(\mathrm{mmol} / \mathrm{L})$ & $1.55[1.10-2.10]$ & $1.30[0.90-1.80]$ & 0.097 \\
\hline $\begin{array}{l}\text { Symptom day on } \\
\text { the ABG }\end{array}$ & $12.50[8.00-17.00]$ & $10[7.00-13.00]$ & 0.070 \\
\hline \multicolumn{4}{|l|}{ Hemogram } \\
\hline $\mathrm{Hb}(\mathrm{mg} / \mathrm{dL})$ & 11.55 [10.30-13.45] & $12.70[10.40-13.80]$ & 0.226 \\
\hline Hematocrit (\%) & 35.75 [32.05-39.25] & $36.30[32.40-41.40]$ & 0.347 \\
\hline $\begin{array}{l}\text { Platelet count } \\
\left(10^{3} / \mathrm{mm}^{3}\right)\end{array}$ & $234.50[179.75-308.25]$ & $238.00[201.00-319.00]$ & 0.744 \\
\hline $\begin{array}{l}\text { Leucocyte } \\
\left(10^{3} / \mathbf{m m}^{3}\right)\end{array}$ & $8.67[6.45-10.30]$ & $9.72[6.57-12.02]$ & 0.083 \\
\hline $\begin{array}{l}\text { Neutrophil } \\
\left(10^{3} / \mathbf{m m}^{3}\right)\end{array}$ & $6.58[4.06-7.83]$ & $8.47[5.52-10.99]$ & 0.003 \\
\hline $\begin{array}{l}\text { Lymphocyte } \\
\left(10^{3} / \mathrm{mm}^{3}\right)\end{array}$ & $1.28[0.91-1.89]$ & $0.68[0.52-0.90]$ & $<0.001$ \\
\hline
\end{tabular}




\begin{tabular}{|c|c|c|c|}
\hline & $\begin{array}{l}\left|\mathrm{SpO}_{2}-\mathrm{SaO}_{2}\right|[?] 4 \%(\mathrm{n}: \\
58)\end{array}$ & $\begin{array}{l}\left|\mathrm{SpO}_{2}-\mathrm{SaO}_{2}\right|>4 \%(\mathrm{n}: \\
59)\end{array}$ & $\mathrm{p}$ \\
\hline \multicolumn{4}{|l|}{ Other } \\
\hline D-dimer $(\mathrm{ng} / \mathrm{mL})$ & $288.00[200.50-441.75]$ & $447[272.00-1298.00]$ & 0.002 \\
\hline Ferritin $(\mathrm{ng} / \mathrm{mL})$ & $206.50[83.07-352.75]$ & $683.00[345.00-979.00]$ & $<0.001$ \\
\hline Fibrinogen $(\mathrm{g} / \mathrm{dL})$ & $3.92[2.90-4.90]$ & $5.23[4.35-6.42]$ & $<0.001$ \\
\hline CRP $(\mathrm{mg} / \mathrm{L})$ & $17.40[5.82-59.12]$ & $110.00[68.90-140.30]$ & $<0.001$ \\
\hline $\begin{array}{l}\mathrm{PaO}_{2} \text { : partial arterial } \\
\text { oxygen pressure, }\end{array}$ & $\begin{array}{l}\mathrm{PaO}_{2} \text { : partial arterial } \\
\text { oxygen pressure, }\end{array}$ & $\begin{array}{l}\mathrm{PaO}_{2}: \text { partial arterial } \\
\text { oxygen pressure, }\end{array}$ & $\begin{array}{l}\mathrm{PaO}_{2} \text { : partial arterial } \\
\text { oxygen pressure, }\end{array}$ \\
\hline $\mathrm{PaCO}_{2}:$ partial & $\mathrm{PaCO}_{2}:$ partial & $\mathrm{PaCO}_{2}:$ partial & $\mathrm{PaCO}_{2}$ : partial \\
\hline $\begin{array}{l}\text { arterial carbon dioxide } \\
\text { pressure, } \mathbf{S a O}_{2} \text { : }\end{array}$ & $\begin{array}{l}\text { arterial carbon dioxide } \\
\text { pressure, } \mathbf{S a O}_{2} \text { : }\end{array}$ & $\begin{array}{l}\text { arterial carbon dioxide } \\
\text { pressure, } \mathbf{S a O}_{2} \text { : }\end{array}$ & $\begin{array}{l}\text { arterial carbon dioxide } \\
\text { pressure, } \mathbf{S a O}_{2} \text { : }\end{array}$ \\
\hline arterial oxygen & arterial oxygen & arterial oxygen & arterial oxygen \\
\hline pressure, $\mathbf{H C O 3}^{-}$: & pressure, $\mathbf{H C O}^{-}$: & pressure, $\mathbf{H C O}^{-}$: & pressure, $\mathbf{H C O}^{-}$: \\
\hline bicarbonate, ABG: & bicarbonate, ABG: & bicarbonate, ABG: & bicarbonate, ABG: \\
\hline arterial blood gases, & arterial blood gases, & arterial blood gases, & arterial blood gases, \\
\hline $\begin{array}{l}\text { CRP: C-reactive } \\
\text { protein }\end{array}$ & $\begin{array}{l}\text { CRP: C-reactive } \\
\text { protein }\end{array}$ & $\begin{array}{l}\text { CRP: C-reactive } \\
\text { protein }\end{array}$ & $\begin{array}{l}\text { CRP: C-reactive } \\
\text { protein }\end{array}$ \\
\hline
\end{tabular}

Table 3. Binary logistic regression analysis between large difference on $\mathrm{SpO} 2-\mathrm{SaO} 2$ and other clinical variables.

\begin{tabular}{lllll}
\hline & Univariate analyses & Univariate analyses & Multivariate analyses & Multivari \\
\hline & OR (95\% CI) & P-value & P-value & OR (95\% \\
Age & $1.000(0.970-1.030)$ & 0.985 & 0.985 & $1.322(0.42$ \\
Gender (male) & $2.800(1.269-6.176)$ & 0.011 & 0.011 & \\
Lactate & $0.643(0.358-1.156)$ & 0.140 & 0.140 & $1.018(0.95$ \\
Leucocyte & $1.077(0.978-1.187)$ & 0.132 & 0.132 & $0.107(0.03$ \\
Neutrophil & $1.168(1.045-1.306)$ & 0.006 & $<0.001$ & $1.072(0.98$ \\
Lymphocyte & $0.076(0.025-0.236)$ & $<0.001$ & 0.130 & $1.155(1.00$ \\
D-dimer (per 100 unit) & $1.120(1.029-1.218)$ & 0.130 & $<0.001$ & $1.705(1.07$ \\
Ferritin (per 100 unit) & $1.317(1.150-1.507)$ & $<0.001$ & $<0.001$ & $1.098(0.98$ \\
Fibrinogen & $1.913(1.426-2.568)$ & $<0.001$ & $<0.001$ & CRP: C-r \\
CRP (per 10 unit) & $1.242(1.141-1.351)$ & $<0.001$ & CRP: C-reactive protein & CR: C-reactive protein \\
CRP: C-reactive protein & CRP: C-reactive protein & CRP: & & \\
\hline
\end{tabular}

\section{Figure Legends}

Figure 1. Flowchart of study patients

Figure 2 . Bland-Altman plots for comparing $\mathrm{SpO}_{2}$ with $\mathrm{SaO}_{2}$ within the total study group. The X-axis represents the mean of $\mathrm{SpO}_{2}$ and $\mathrm{SaO}_{2}\left(\left(\mathrm{SpO}_{2}+\mathrm{SaO}_{2}\right) / 2\right)$ and the Y-axis represents the difference between $\mathrm{SpO}_{2}$ and $\mathrm{SaO}_{2}\left(\mathrm{SpO}_{2}-\mathrm{SaO}_{2}\right)$. Red line shows the mean bias. Blue lines represent upper and lower limits of agreement at $\pm 1.96 \mathrm{SD}$.

Figure 3. Bland-Altman plots for comparing $\mathrm{SpO}_{2}$ with $\mathrm{SaO}_{2}$ among patients with normal serum fibrinogen $(<4.8 \mathrm{~g} / \mathrm{dL})(\mathrm{A})$ and with high serum fibrinogen ([?]4.8 g/dL) (B). The X-axis represents the mean of $\mathrm{SpO}_{2}$ and $\mathrm{SaO}_{2}\left(\left(\mathrm{SpO}_{2}+\mathrm{SaO}_{2}\right) / 2\right)$ and the $\mathrm{Y}$-axis represents the difference between $\mathrm{SpO}_{2}$ and $\mathrm{SaO}_{2}\left(\mathrm{SpO}_{2}-\mathrm{SaO}_{2}\right)$. Red line shows the mean bias. Blue lines represent upper and lower limits of agreement at $+-1.96 \mathrm{SD}$. The mean difference was higher in patients with high fibrinogen levels than those with normal levels $(5.07+-2.44$ 
vs $2.98+-2.44, \mathrm{p}<0.001)$.

Figure 4. Bland-Altman plots for comparing $\mathrm{SpO}_{2}$ with $\mathrm{SaO}_{2}$ among patients with normal serum ferritin level $(<228 \mathrm{ng} / \mathrm{mL})(\mathrm{A})$ and with increased serum ferritin $([?] 228 \mathrm{ng} / \mathrm{mL})(\mathrm{B})$. The $\mathrm{X}$-axis represents the mean of $\mathrm{SpO}_{2}$ and $\mathrm{SaO}_{2}\left(\left(\mathrm{SpO}_{2}+\mathrm{SaO}_{2}\right) / 2\right)$ and the Y-axis represents the difference between $\mathrm{SpO}_{2}$ and $\mathrm{SaO}_{2}$ $\left(\mathrm{SpO}_{2}-\mathrm{SaO}_{2}\right)$. Red line shows the mean bias. Blue lines represent upper and lower limits of agreement at +$1.96 \mathrm{SD}$. The mean difference was higher in patients with high ferritin levels than those with normal levels $(4.88+-2.46$ vs $2.41+-2.22, \mathrm{p}<0.001)$.

Figure 5. Bland-Altman plots for comparing $\mathrm{SpO}_{2}$ with $\mathrm{SaO}_{2}$ among patients with normal lymphocyte count $\left(>1.04 \times 10^{3} / \mathrm{mm}^{3}\right)(\mathrm{A})$ and low lymphocyte count ([?]1.04 $\left.\mathrm{x} 10^{3} / \mathrm{mm}^{3}\right)(\mathrm{B})$. The X-axis represents the mean of $\mathrm{SpO}_{2}$ and $\mathrm{SaO}_{2}\left(\left(\mathrm{SpO}_{2}+\mathrm{SaO}_{2}\right) / 2\right)$ and the $\mathrm{Y}$-axis represents the difference between $\mathrm{SpO}_{2}$ and $\mathrm{SaO}_{2}$ $\left(\mathrm{SpO}_{2}-\mathrm{SaO}_{2}\right)$. Red line shows the mean bias. Blue lines represent upper and lower limits of agreement at $+-1.96 \mathrm{SD}$. The mean difference was higher in patients with low lymphocyte count than those with normal levels $(5.07+-2.36$ vs $2.66+-2.39, \mathrm{p}<0.001)$.

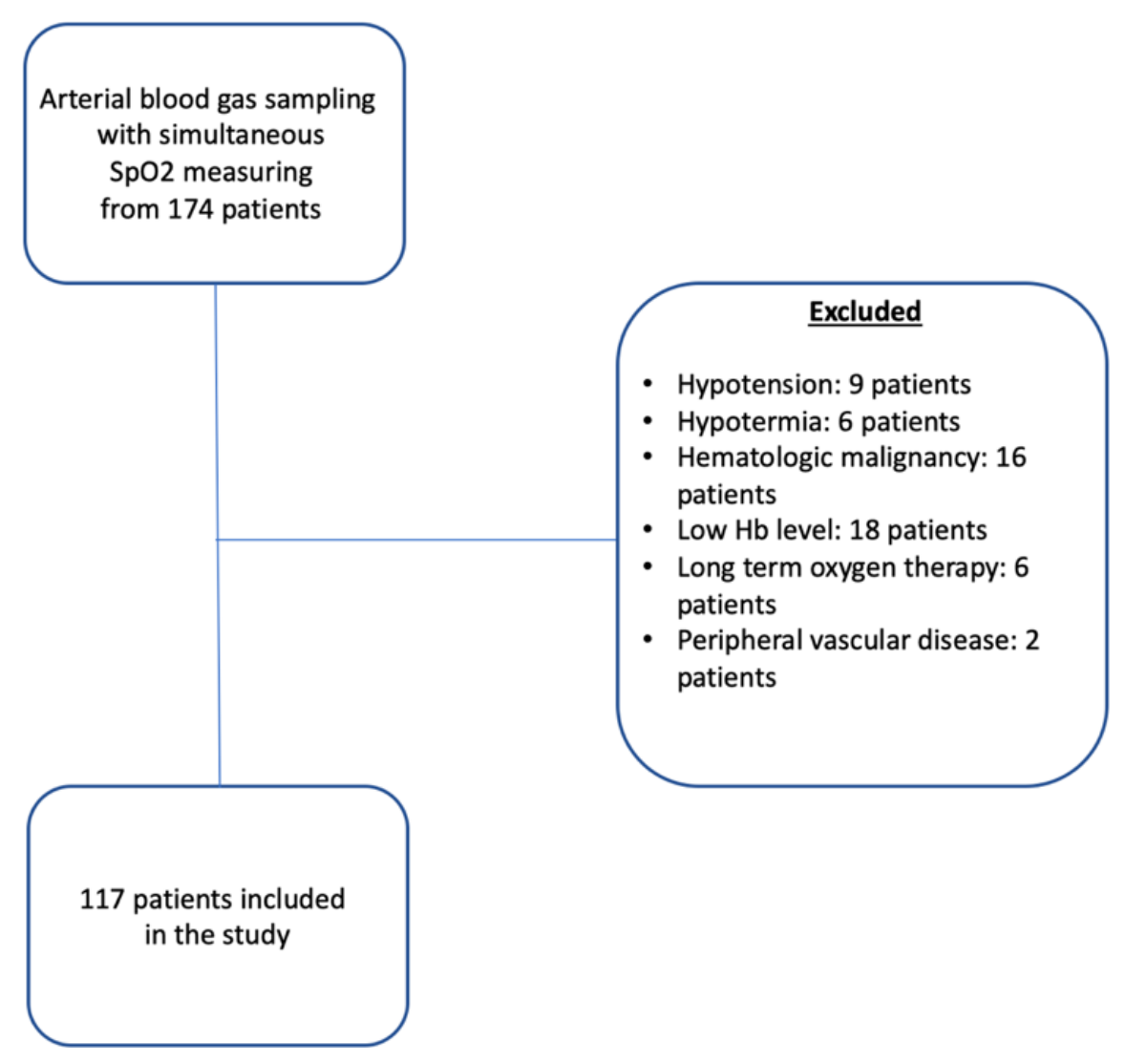



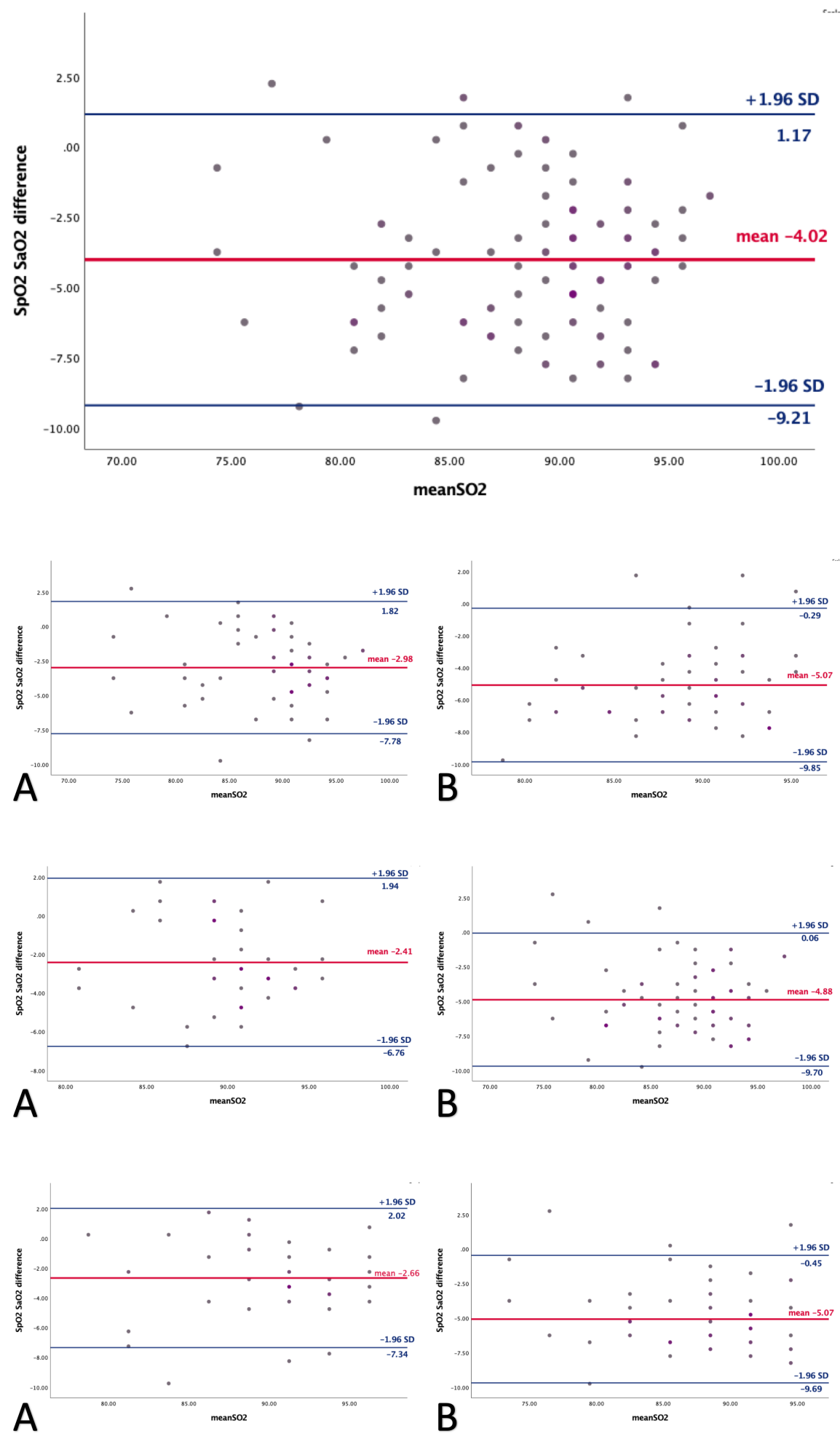